\title{
Dental Age, Agenesis, and Morphology in Patients With Operated Single-Suture Craniosynostoses
}

\section{Leinonen, Sami}

2021-03

Leinonen , S , Rice , D , Leikola , J \& Heliövaara , A 2021 , ' Dental Age, Agenesis, and Morphology in Patients With Operated Single-Suture Craniosynostoses ' , Cleft Palate Craniofacial Journal , vol. 58 , no. 3 , pp. 290-298 . https://doi.org/10.1177/1055665620950145

http://hdl.handle.net/10138/339712

https://doi.org/10.1177/1055665620950145

acceptedVersion

Downloaded from Helda, University of Helsinki institutional repository.

This is an electronic reprint of the original article.

This reprint may differ from the original in pagination and typographic detail.

Please cite the original version. 


\title{
Dental Age, Agenesis, and Morphology in Patients With Operated Single-Suture Craniosynostoses
}

The Cleft Palate-Craniofacial Journal $1-9$ (C) 2020, American Cleft PalateCraniofacial Association Article reuse guidelines: sagepub.com/journals-permissions DOI: I0.I I77//055665620950|45 journals.sagepub.com/home/cpc (S)AGE

\author{
Sami Leinonen, DDS $^{\prime} \oplus$, David Rice, BDS, PhD $^{2}$, \\ Junnu Leikola, MD, PhD, DDS', and Arja Heliövaara, DDS, PhD $^{\prime}{ }^{\circledR}$
}

\begin{abstract}
Objective: The aim of this study was to evaluate the dental age, agenesis, and morphology of children with surgically operated single-suture craniosynostoses from orthopantomographs.

Design: A single-centered cross-sectional observational archival study.

Patients: A sample of 196 Finnish patients with single-suture craniosynostosis without additional birth defects or syndromes (excluding Muenke syndrome) was included in this study.

Main Outcome Measures: Dental age was assessed using the method developed by Demirjian et al. and modified by Nyström et al. for the Finnish population. Methods described by Tulensalo et al. and Oehlers et al. were used to study taurodontism and dens invaginatus, respectively.

Results: The study sample of 149 patients was divided into 3 groups: patients with sagittal synostosis $(n=103)$, coronal synostosis $(n=25)$, and metopic synostosis $(n=21)$. Orthopantomographs taken on average at ages 8.20 to 8.33 were used. The dental ages in different groups were on average $0.37,0.60$, and 0.66 years ahead of normative values, for sagittal, coronal, and metopic groups, respectively. Tooth agenesis, taurodontism, and invaginated teeth were found in all groups with invaginations having a high prevalence. Peg-shaped upper lateral incisors and one geminated lower lateral incisor were also found.

Conclusions: These descriptive data may help improve dental care in patients with single-suture craniosynostosis.
\end{abstract}

\section{Keywords}

craniosynostosis, dental age, dental morphology, dental development, tooth agenesis

\section{Introduction}

Craniosynostosis, the premature fusion of 1 or more of the cranial sutures, is a relatively common birth defect, with reported prevalence of 3.1 to 7.2 per 10000 live births (French et al., 1990; Boulet et al., 2008; Cornelissen et al., 2016). Craniosynostosis can be either nonsyndromic or syndromic, of which the former is by far more common (Lajeunie et al., 1995; Di Rocco et al., 2009; Ko, 2016). Premature closure of the sagittal suture covers $40 \%$ to $55 \%$ of patients with isolated nonsyndromic craniosynostosis. Other single-suture craniosynostoses include fusion of the coronal $(20 \%-25 \%)$, metopic (5\%-15\%), and lambdoid (<5\%) sutures (Ko, 2016). It has been proposed that the prevalence of isolated sagittal and metopic synostoses may be increasing, with its cause being unknown (Di Rocco et al., 2009; Cornelissen et al., 2016).

Craniosynostosis impairs the growth of the cranial vault perpendicular to the affected suture and leads to compensatory growth at other patent sutures, which may result in abnormal skull shape (Twigg and Wilkie, 2015; Kajdic et al., 2018). Craniosynostosis may lead to intracranial hypertension especially in syndromic cases, as well as sensory, respiratory, and neurodevelopmental difficulties (Knight et al., 2014; Maliepaard et al., 2014; Christian et al., 2015; Twigg and Wilkie, 2015; Kajdic et al., 2018).

\footnotetext{
' Department of Plastic Surgery, Cleft Palate and Craniofacial Center, Helsinki University Hospital, Helsinki, Finland

${ }^{2}$ Department of Oral and Maxillofacial Diseases, University of Helsinki and Helsinki University Hospital, Helsinki, Finland
}

\section{Corresponding Author:}

Sami Leinonen, Department of Plastic Surgery, Cleft Palate and Craniofacial Center, Helsinki University Hospital, PO Box 266, HUS Fl-00029, Finland.

Email: samioskari.leinonen@gmail.com 
The Cleft Palate-Craniofacial Journal $X X(X)$

The etiology of craniosynostosis is multifactorial with both environmental and genetic factors. Intrauterine fetal head constraint, teratogenic agents, medications such as the antiepileptic drug valproate, maternal smoking and alcohol use, single-gene mutations, chromosomal abnormalities, and polygenic background predispose to craniosynostosis (Johnson and Wilkie, 2011; Bessenyei et al., 2015; Twigg and Wilkie, 2015).

The genetics and molecular patterns involved in cranial suture development are complex (Rice et al., 2003). Isolated forms of craniosynostosis are usually sporadic with polygenic and epigenetic factors and with low sibling recurrence risk (Johnson and Wilkie, 2011; Timberlake and Persing, 2018). The genetic causes of craniosynostosis have been identified from syndromic cases, which include the mutations in FGFR-1 (Pfeiffer syndrome), FGFR-2 (Apert syndrome), FGFR-3 (Muenke syndrome), TWISTI (Saethre-Chotzen syndrome), ENFB1 (craniofrontonasal syndrome), RAB-23 (Carpenter syndrome), and many others (Johnson and Wilkie, 2011; Twigg and Wilkie, 2015; Wilkie et al., 2017; Timberlake and Persing, 2018).

Dental development is regulated by complex epithelialmesenchymal interactions. Neural crest-derived mesenchyme goes through multiple stages of development to reach unique morphological features of the complete tooth. Genetic regulation strongly determines the process of dental development and thus the many dental anomalies result from gene mutations (Jernvall and Thesleff, 2012; Thesleff, 2014). Over 100 genes involved in dental development have been studied (Jernvall and Thesleff, 2012; Thesleff, 2014). Dental anomalies are fairly common with reported prevalence ranging from $20.9 \%$ to $56.9 \%$ in patients in different study populations (GoncalvesFilho et al., 2014; Lagana et al., 2017; Baron et al., 2018; Bilge et al., 2018). Dental anomalies include a multitude of changes from morphological alterations such as taurodontism and invaginations studied in this article to missing or supernumerary teeth and positional aberrations (Goncalves-Filho et al., 2014; Lagana et al., 2017; Baron et al., 2018; Bilge et al., 2018). Taurodontism is defined as a developmental anomaly where the pulp chamber of the tooth is elongated with apical displacement of the furcation in molars (Tulensalo et al., 1989; Jafarzadeh et al., 2008). Invaginations of teeth are a defined as a developmental anomaly caused by an invagination of the enamel organ into the dental papilla that leads to an enamel infolding into dentine in the mature tooth (Oehlers, 1957; Gallagher et al., 2016).

Similar gene networks regulate skull and tooth morphogenesis (Yuan and Chai, 2019). Occlusal characteristics are been studied in patients with isolated craniosynostosis, proposing interesting results in alterations in craniofacial growth patterns (Pelo et al., 2011; Heliövaara et al., 2015; Lebuis et al., 2015). Retrognathic mandibles in patients with scaphocephaly and dentoskeletal asymmetry occurring in tandem with coronal synostosis have been reported (Pelo et al., 2011; Heliövaara et al., 2015; Lebuis et al., 2015). Considering dental development, there has been reports of altered dental maturation and morphology in syndromic cases of craniosynostosis (Reitsma et al., 2014a; Reitsma et al., 2014b; Woods et al., 2015). The dental characteristics in nonsyndromic cases of craniosynostosis, on the other hand, have received less attention. The aim of this study was to look into the dental development and morphology in patients with single-suture craniosynostosis.

\section{Material and Methods}

\section{Ethical Approval}

The protocol of this retrospective study was approved by the Hospital District of Helsinki and Uusimaa (HUS/221/2017 $\S 47)$ and adhered to the principles outlined in the Declaration of Helsinki. Consent was acquired from the patients' parents for the use of clinical photographs and radiographs presented in this article.

\section{Overview}

A sample of 196 Finnish patients born in between 1997 and 2010 with surgically operated single-suture craniosynostoses including patients with Muenke syndrome (with coronal synostosis) was included in this study.

Dental age, number of missing teeth excluding the third molars, number of taurodontic first molars, invaginations, and other possible changes in dental morphology were investigated. Dependent Student $t$ test was used to calculate confidence intervals and $P$ values for dental age comparing chronological age to dental age in each of the 3 groups. The Holm-Bonferroni method was used to adjust the $P$ values to take into account potential problems arising from multiple comparisons. Cohen $\kappa$ scores were used to calculate intrarater level of agreement for dental age and taurodontism by reassessing 20 randomly selected patients a month after the primary assessment (patients chosen with online randomization software). Statistical analyses were carried out in RStudio.

The orthopantomographs (OPGs) used in this study were taken between the years 1999 and 2019 on average at ages $8.20,8.24$, and 8.33 years, respectively, for patients in the sagittal, coronal, and metopic groups. The orthopantomographs were taken with different equipment in different time periods, including Oriola PM 2002 CC (operating 1992-2010, magnification value of 1.3), GE Orthopantomograph OP 100 (operating 2001-2013, magnification value of 1.28), and Instrumentarium Orthopantomograph OP200 D (present, magnification value of 1.3).

\section{Dental Age Assessment}

Dental age was assessed from OPGs taken at 8 years of age. The developmental stages of 7 left mandibular permanent teeth were assessed as described by Demirjian et al. (1973) (Figure 1A and B). If a left mandibular permanent tooth was missing, a contralateral tooth was used. The teeth were scored depending on their developmental status on an 8-stage scale from A to $\mathrm{H}$. For each developmental stage, a biologically weighted score for Finnish males and females were used. In 


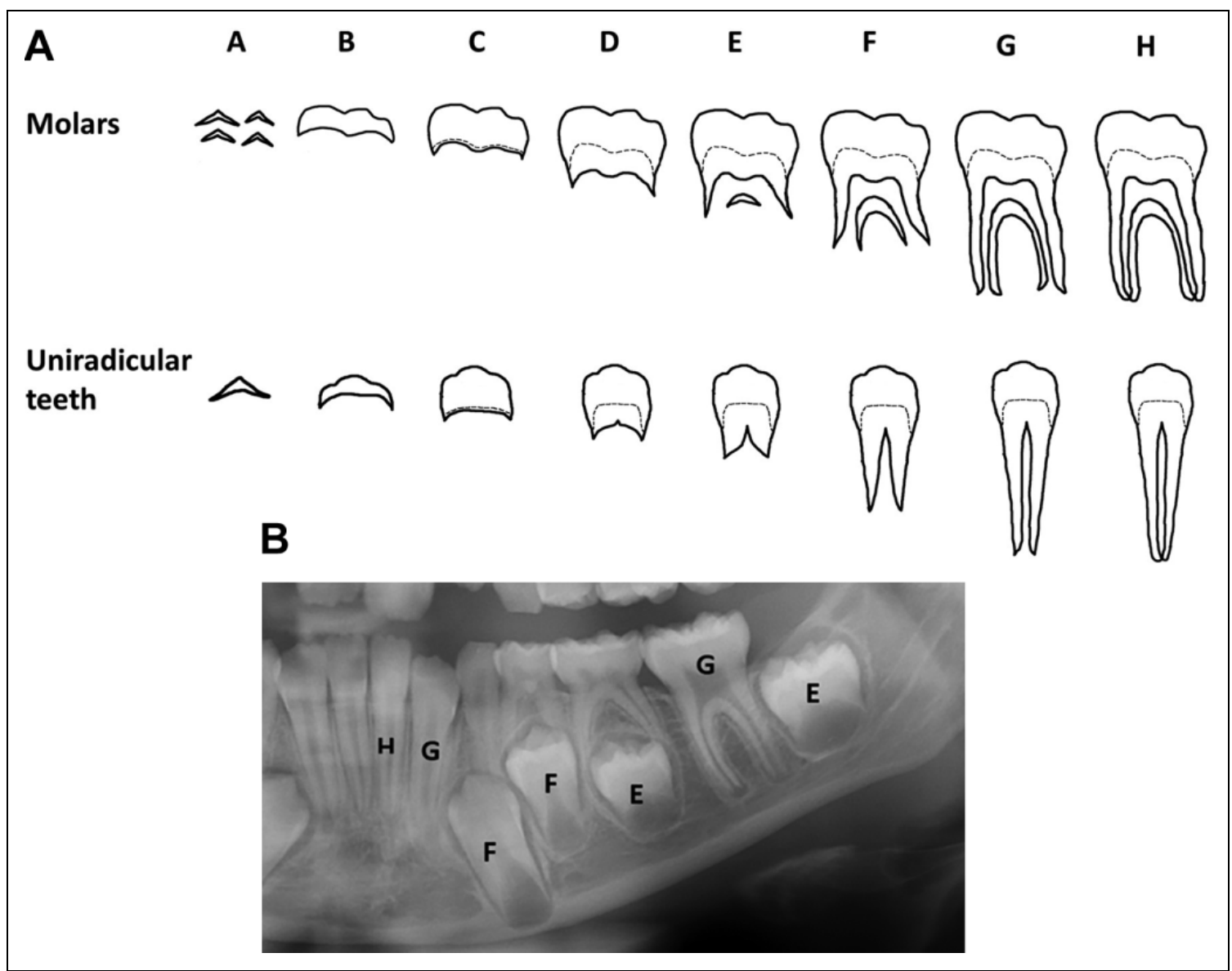

Figure I. A Developmental stages of molars and uniradicular teeth redrawn from Demirjian et al. (1973). The stages are clearly defined

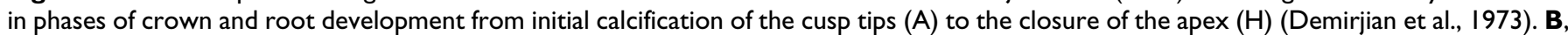
A section of an orthopantomograph showing the 7 lower left mandibular teeth with their corresponding developmental stages superimposed on them.

cases of missing permanent teeth bilaterally ( $\mathrm{n}=5$, all missing the left and right second premolar), we used an equation described by Nyström et al. (2000) for scoring missing teeth. The sum of the 7 scores was then converted into dental age using Finnish reference values. Confidence intervals and $P$ values comparing dental and chronological ages was calculated with dependent Student $t$ test, and Cohen $\kappa$ scores for each left mandibular tooth was used to calculate intrarater level of agreement.

\section{Taurodontism}

The presence of taurodontic first permanent molars was assessed from the OPGs as described by Tulensalo et al. (1989), a modification of the method described by Shifman and Chanannel (1978) that takes into account OPG magnification up to 1.32-fold compared to periapical and bitewing radiographs. Measurement 3 (in millimeters) as proposed by Tulensalo et al. (1989) was used for first molars with incomplete root formation and open root apexes, where the distance from the cementoenamel junction of the tooth to the pulp chamber floor estimates the degree of taurodontism (Figure 2).
Hypotaurodontism was defined as a range of 3.5 to $5.0 \mathrm{~mm}$, mesotaurodontism 5.5 to $7.0 \mathrm{~mm}$, and hypertaurodontism $7.5 \mathrm{~mm}$ or over (Tulensalo et al., 1989).

In this study, the OPGs of patients were taken during different time periods with different equipment. While the OPGs taken with older equipment $(n=64)$ included magnification, the newer OPGs taken with the present equipment $(n=85)$ had magnification eliminated from the radiographs in the image viewing software. To correct this error in magnification between the groups, we multiplied the values of measurement 3 in the newer OPGs by the manufacturer's listed magnification value of 1.3 .

\section{Invaginations}

Invaginations were assessed not only on OPGs (8 years) but also on cone-beam computed tomography (CBCT), computed tomography (CT), OPGs taken at different ages, and clinical dental photographs if available. All CTs were obtained using a 64-slice scanner (LightSpeed VCT). The following parameters were used: helical full, 0.5 -second rotation time, increment of $39.37 \mathrm{~mm} /$ rotation (pitch $0.984: 1$ ), and $100 \mathrm{kV}$ at $40 \mathrm{~mA}$ and 


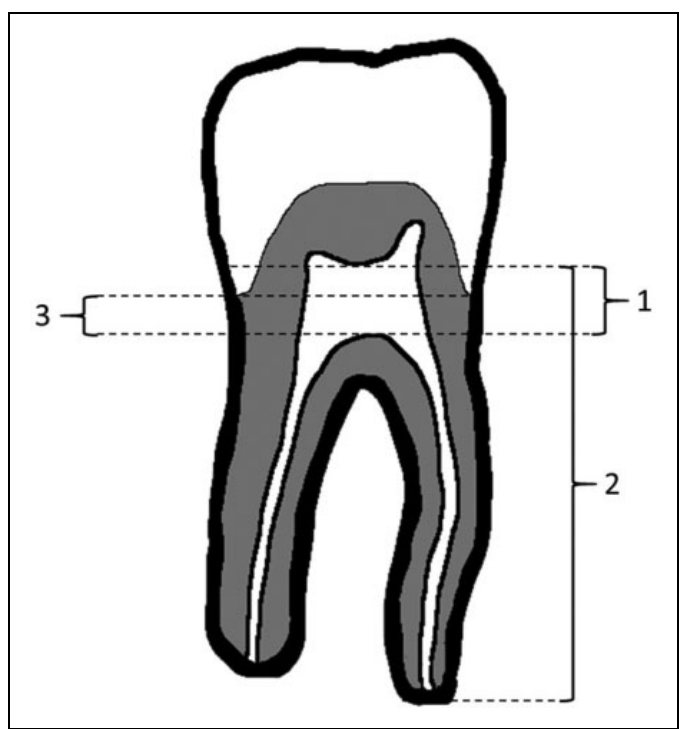

Figure 2. The measurements used to determine the degree of taurodontism (Tulensalo et al., 1989). Measurement $I$ is the height of the pulp chamber, measurement 2 is the distance from the roof of the pulp chamber to the root apex, and measurement 3 the distance between the lines drawn through the cementoenamel junctions to the floor of the pulp chamber. Measurement 3 was used in this study in molars with incomplete root development.

$120 \mathrm{kV}$ at $50 \mathrm{~mA}$ of tube current for those aged less and over 1.5 , respectively, with images reconstructed at a thickness of $0.625 \mathrm{~mm}$ at $0.312-\mathrm{mm}$ intervals (Leikola et al., 2014). Invaginations of teeth were classified according to the Oehlers classification system (Oehlers, 1957). In the Oehlers classification system, 3 types of coronal invaginations exist depending on the severity of the invagination, from type 1 to type 3 . A type 1 invagination is confined within the crown, a type 2 invagination invades within the root with possible pulpal communication, and a type 3 invagination penetrates through the root apically or laterally, creating a so-called "second foramen" with usually no communication with the pulp (Oehlers, 1957). In some rare occasions, the invagination can affect a tooth's root (radicular invagination). Only a couple of cases of radicular invagination have been described in the literature (Oehlers, 1958; Bhatt Dholakia, 1975; Neves et al., 2013).

\section{Results}

\section{Sample Characteristics}

After excluding patients with additional malformations (5 patients with cleft lip and/or palate) and patients without or with poor-quality OPGs taken at age $8(n=42)$, the study sample was reduced to 149 patients. Of the 149 patients, 103 (out of which 21 were females) patients had a sagittal suture synostosis, 25 (17 females) had coronal synostosis, and 21 (3 females) had metopic synostosis. In the coronal synostosis group, 7 patients were diagnosed with Muenke syndrome (FGFR3-Pro250Arg).

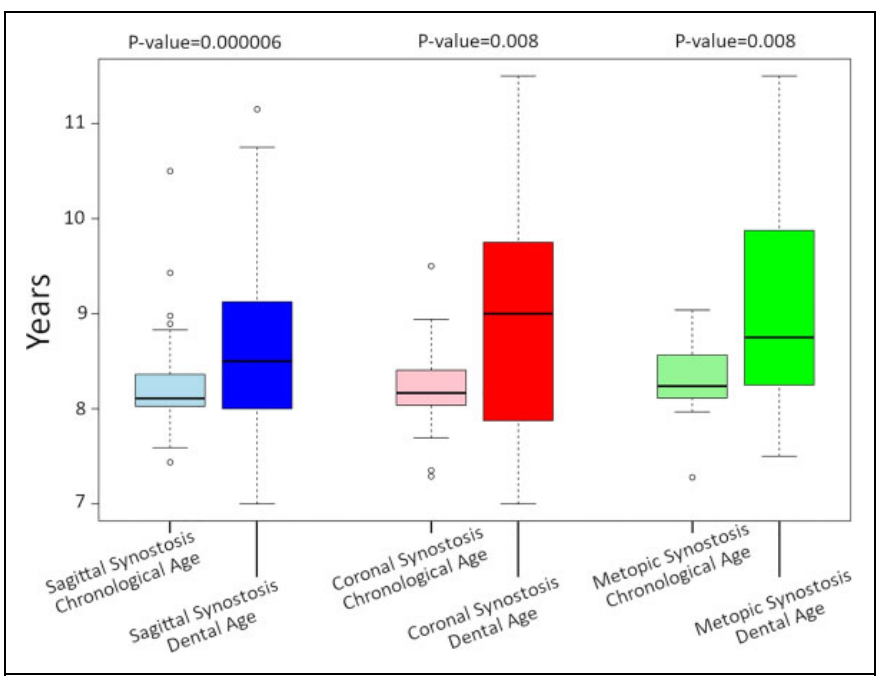

Figure 3. A boxplot in which dental ages in all the 3 groups are shown in comparison with chronological ages. Values on the $y$-axis are in years, with the colored area of the boxplot showing the range of ages from the upper to the lower quartile and the black line in the middle showing the median for the ages. The whiskers of the boxplot present the minimum and maximum values for the ages, expect for when there are outliers (shown as dots, values more than I.5 times the interquartile width above or below the colored area).

\section{Dental Age}

Compared to chronological age, dental age was found to be advanced in all of the 3 groups. Dental age was ahead of chronological age on average 0.37 years in the sagittal synostosis group ( $95 \% \mathrm{CI}, 0.23-0.52), 0.60$ years in the coronal synostosis group (95\% CI, 0.21-0.98), and 0.66 years in the metopic synostosis group (95\% CI, 0.21-1.11), with Holm-Bonferroni corrected $P$ values of $.000006, .008$, and 0.008 , respectively (Figure 3). In the coronal synostosis group, patients with ( $\mathrm{n}=$ 7) and without $(\mathrm{n}=18)$ Muenke syndrome showed no statistically significant difference when compared to each other $(P$ value .90$)$.

In interpreting the $\kappa$ scores, following guidelines provided by Cicchetti et al. (1994) were used: Less than 0.4 was considered poor, 0.40 to 0.59 fair, 0.60 to 0.74 good, and 0.75 to 1 excellent level of agreement. A mean calculated Cohen $\kappa$ score of 0.89 for dental age indicates excellent intrarater agreement.

\section{Dental Agenesis}

A total of 19 teeth were found missing in the 3 groups. The prevalence for hypodontia (6 or less missing teeth) was $9 \%$ in the sagittal synostosis group, $8 \%$ in the coronal synostosis group, and $10 \%$ in the metopic synostosis group. In the sagittal synostosis group, 11 lower second premolars were found missing, with also 1 upper lateral incisor and 1 upper second premolar missing. Of the lower second premolars, 8 were missing in 4 patients bilaterally. In the coronal synostosis group, one patient lacked 2 lower lateral incisors and another patient lacked 1 upper lateral incisor. In the metopic synostosis group, 
Table I. Number of Missing Teeth With Numbers and Percentages of Patients Missing Teeth From Each Group.

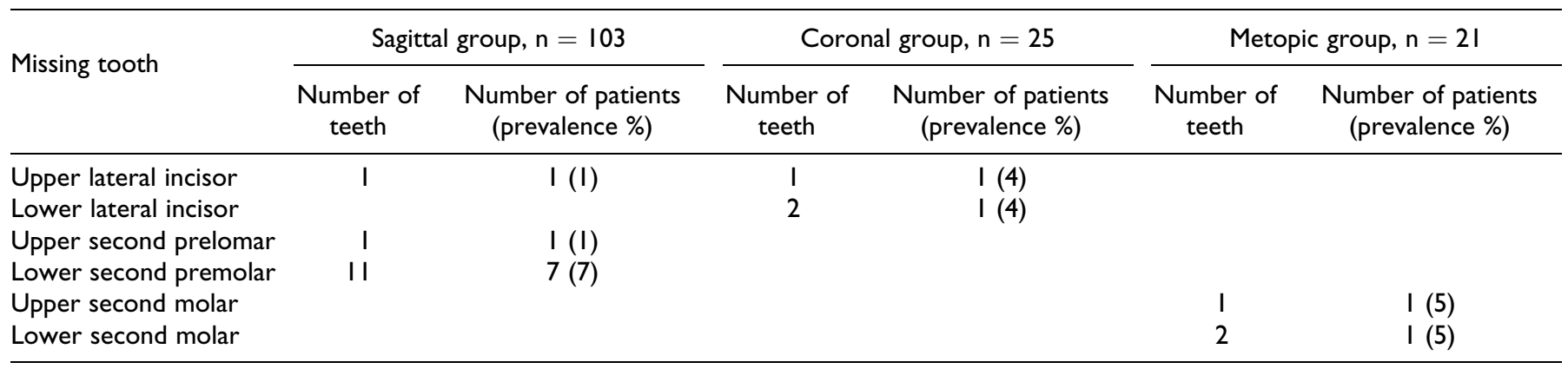

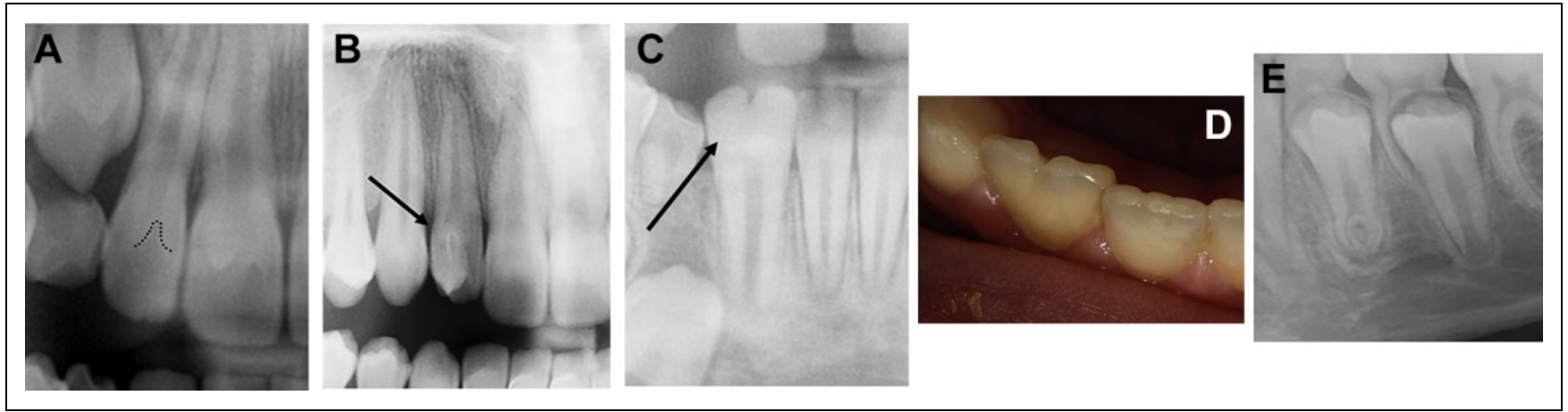

Figure 4. A, An Oehlers class I invagination in an upper lateral incisor outlined with dots. B, The arrow points toward an Oehlers class 2 invagination in an upper lateral incisor. C, A geminated lower lateral incisor in a patient with metopic synostosis in a periapical radiograph. D, Clinical photograph of the geminated lower lateral incisor. E, A left mandibular first premolar with an atypical root bifurcation.

1 upper and 2 lower second molars were missing, the lower molars being missing in the same patients. The missing teeth are presented in Table 1 . Only 1 supernumerary tooth was found in the sagittal synostosis group in the anterior maxilla.

\section{Morphological Anomalies}

Taurodontism. The assessment of 1 or more molars was not possible in 11 patients who had problems in their OPGs. Three patients had orthodontic appliances fixed to upper or lower molars ( 2 quad helixes and 1 lingual arch), 7 patients had poor quality OPGs, and 1 patient had poorly developed upper first molars with no pulpal floor present (root development only just beginning). The prevalence for taurodontism was $35 \%$ in the sagittal synostosis group, $12 \%$ in the coronal synostosis group, and $24 \%$ in the metopic synostosis group. All the molars considered taurodontic were classified as hypotaurodontic. Of the taurodontic molars, $57 \%$ were upper molars and $43 \%$ lower molars. Of the total of 44 patients with hypotaurodontism, 23 patients had only 1 taurodontic first molar, 12 patients had 2 taurodontic molars, 4 patients had 3 taurodontic molars, and 10 patients had all 4 molars hypotaurodontic. Mean Cohen $\kappa$ score was 0.82 , indicating significant intrarater correlation.

Invaginations. Invaginated teeth were found in 24 (23\%) patients in the sagittal synostosis group, in $7(28 \%)$ in the coronal synostosis group, and in $8(33 \%)$ in the metopic synostosis group. Across all the groups, a total of 68 invaginated upper lateral incisors were found, of which 60 were found bilaterally. Nineteen invaginated upper central incisors (18 bilaterally) were also found. Of the invaginated upper incisors, almost all were classified as Oehlers type 1 invaginations (Figure 4A). Only 3 upper lateral incisors classified as Oehlers type 2 invaginations were found (Figure 4B).

Other morphological anomalies. Other morphological anomalies found in this study included 2 peg-shaped upper lateral incisors ( 1 in sagittal and coronal groups each) and a geminated lateral incisor in the metopic synostosis group (Figure 4C and D). We also found 2 mandibular first premolars with atypical root bifurcations in one patient in the sagittal synostosis group (Figure 4E; Llamas and Jimenez-Planas, 1993). Summary of morphological anomalies found in this study is presented in Table 2 .

\section{Discussion}

\section{Dental Age}

In this study, patients in all the 3 groups with different singlesuture craniosynostoses had advanced dental development when compared to chronological age. We are not aware of any association of bone age with nonsyndromic craniosynostosis. Patients with Saethre-Chotzen, Crouzon, and Apert syndromes have been reported to have variable delay in dental maturation 
Table 2. Different Dental Anomalies Found in This Study.

\begin{tabular}{|c|c|c|c|c|c|c|c|c|}
\hline \multirow{6}{*}{$\begin{array}{l}\text { Supernumer } \\
\text { Hypodontia } \\
\text { Taurodontis } \\
\text { Dens invagin } \\
\text { Gemination } \\
\text { Peg-shaped } \\
\text { lateral inci }\end{array}$} & \multirow{2}{*}{\multicolumn{2}{|c|}{$\begin{array}{cc}\text { Sagittal synostosis, } \mathrm{n}=103 \\
\begin{array}{c}\text { Number } \\
\text { of teeth }\end{array} \\
\begin{array}{c}\text { patients } \\
\text { (prevalence \%) }\end{array}\end{array}$}} & \multirow{2}{*}{\multicolumn{2}{|c|}{$\begin{array}{cc}\text { Coronal synostosis, } \mathrm{n}=25 \\
\begin{array}{c}\text { Number } \\
\text { of teeth }\end{array} & \begin{array}{c}\text { patients } \\
\text { (prevalence \%) }\end{array}\end{array}$}} & \multirow{2}{*}{\multicolumn{2}{|c|}{$\begin{array}{cc}\text { Metopic synostosis, } \mathrm{n}=2 \mathrm{I} \\
\begin{array}{c}\text { Number } \\
\text { of teeth }\end{array} & \begin{array}{c}\text { patients } \\
\text { (prevalence \%) }\end{array}\end{array}$}} & \multicolumn{2}{|c|}{ Total, $N=149$} \\
\hline & & & & & & & $\begin{array}{l}\text { Number } \\
\text { of teeth }\end{array}$ & $\begin{array}{c}\text { Number of } \\
\text { patients } \\
\text { (prevalence \%) }\end{array}$ \\
\hline & I & I (I) & & & & & I & I (0.7) \\
\hline & 13 & $9(9)$ & 3 & $2(8)$ & 3 & $2(10)$ & 19 & $13(9)$ \\
\hline & & & & & I (5) & & I & I (I) \\
\hline & I & I (I) & 1 & I (4) & & & 2 & $2(I)$ \\
\hline
\end{tabular}

and bone age when compared to chronological age (Anderson et al., 1996; Reitsma et al., 2014b; Woods et al., 2015). It is well established that the Demirjian method overestimates dental age (Melo and Ata-Ali, 2017; Sobieska et al., 2018). Later adjustments to the Demirjian method have been made by Willems et al. (2001) to provide higher accuracy. The Finnish reference values for scoring dental age by Nyström et al. were calculated from OPGs taken between years 1964 and 1995, and without no modern control group, there could be changes present in dental development in Finnish children nowadays compared to these "historic" data (Nyström et al., 2000). Furthermore, the differences between chronological age and dental age can result from a multitude of variables such as precision of the method, population characteristics, and statistical approach (Woods et al., 2015). In this study, only 1 operator rated the developmental stages of the teeth, which may lead to wrongly estimating dental age. The results should be thus viewed with caution.

\section{Dental Agenesis}

Hypodontia is one of the most common dentofacial deformities in humans (Al-Ani et al., 2017). Hypodontia (excluding the third molars) is present in $5 \%$ to $10 \%$ of the population (Arte et al., 2001; Goncalves-Filho et al., 2014; Lagana et al., 2017; Baron et al., 2018; Bilge et al., 2018), with the premolars and upper lateral incisors being the most commonly missing teeth (Arte et al., 2001). It is most often nonsyndromic, but it can be related to syndromes and anomalies such as cleft lip and palate (De Coster et al., 2009; Chhabra et al., 2014). It is interesting to note that dental agenesis seems to support Butler's Field Theory, where the distal teeth within each morphogenic class are the most variable (Kieser, 1968). In this study, we found similar frequencies for hypodontia as reported in the general population. Peg-shaped upper lateral incisors, which were also found in this study $(\mathrm{n}=2)$, have been related to hypodontia (Arte et al., 2001).

Only 1 supernumerary tooth was found in this study. In the study's OPGs taken around age 8 , where some teeth have just begun their formation, the presence of tooth agenesis and supernumeraries may be difficult to ascertain.

\section{Taurodontism}

Taurodontism is caused by the failure of the invagination process of the Hertwig epithelial sheath, where it does so at an abnormal horizontal level (Tulensalo et al., 1989; Jafarzadeh et al., 2008). Taurodontism has been linked to various syndromes and anomalies, including Down syndrome, Klinefelter syndrome, and amelogenesis imperfecta (Tulensalo et al., 1989). Taurodontism is a relatively common developmental anomaly in the dentition, with prevalences varying from less than $1 \%$ to $40 \%$ found in the literature (Tulensalo et al., 1989; Goncalves-Filho et al., 2014; Lagana et al., 2017; Baron et al., 2018; Bilge et al., 2018). The prevalences for taurodontism in patients with isolated craniosynostosis found in this study are in line with other studies on different study populations. The second permanent molars were excluded from this study due to their stage of development. In this study, only hypotaurodontic molars were found. When comparing hypotaurodontic molars to nontaurodontic molars as classified by Tulensalo et al. (1989), the line between affected and nonaffected teeth can be somewhat obscure (Tulensalo et al., 1989). Furthermore, even though measurement 3 as presented by Tulensalo et al. (1989) has been well validated for use in assessing taurodontism, it is prone to error resulting from variability in tooth size and angulation. Different systems do exist for assessing taurodontism, but they are often designed for mature teeth with closed apices (in this study, the majority of the teeth had open apices).

Nevertheless, taurodontism should be considered when treating patients with craniosynostosis. Patients with craniosynostosis have been reported to have higher risk for oral diseases, including dental caries, which if untreated may require root canal treatment (Mustafa et al., 2001; Vilan Xavier et al., 2008). Root canal treatment can be difficult due to the taurodontic teeth complex root canal system, apically displaced root canal orifices, and possible canal obliteration (Jafarzadeh et al., 2008).

\section{Invaginations}

The prevalence of dens invaginatus in patients with singlesuture craniosynostosis found in this study (26\%) is higher than 
reported in the general population (ranging from $0.04 \%$ to 10\%; Gunduz et al., 2013; Capar et al., 2015; Gallacher et al., 2016; Zhu et al., 2017). Periapical radiographs and OPGs are commonly used to diagnose invaginations, although they cannot accurately demonstrate the complex anatomy of the invagination or the root canal system adjacent to it (Zhu et al., 2017). Ideally, invaginations can be diagnosed with 3dimensional images (Capar et al., 2015; Zhu et al., 2017). In this study, OPGs were used to study invaginations with CT images if available. The presence of invaginations in OPGs have been reported to be much lower than in CBCT imaging (Capar et al., 2015). This could also affect the results in this study for in some OPGs, the anterior section is poorly imaged with possible rotations in teeth preventing assessment.

With high prevalence of invaginations in patients with isolated craniosynostosis found in this study, clinicians should concentrate on prophylactic care of affected teeth (Gallacher et al., 2016). Invaginated teeth are thought to be the more prone to oral diseases such as dental caries and various pulpal pathologies if there is a communication from the invagination to the pulp (Oehlers, 1957; Capar et al., 2015; Zhu et al., 2017). Invaginations should be treated as soon as they are detected with acid-etched flowable composites to prevent caries development and subsequent pulpal pathologies (Gallagher et al., 2016).

\section{Other Morphological Anomalies}

Gemination is rarely encountered with reported prevalence varying from $0 \%$ to $0.28 \%$ in the general population (Shashirekha and Jena, 2013; Baron et al., 2018). One geminated lower lateral incisor was found in the metopic synostosis group. Geminated teeth can potentially interfere with occlusion and complicate other dental treatment because of their complex morphology.

\section{Clinical Importance}

Patients with isolated craniosynostosis require multidisciplinary care for treating the craniosynostosis itself and the other health issues these patients may present with (Vargervik et al., 2012). Dental and orthodontic care should be considered important in patients with isolated craniosynostosis, with studies revealing possible increased need for care in the dentition and occlusion (Mustafa et al., 2001; Dalben et al., 2006; Pelo et al., 2011; Heliövaara et al., 2015; Lebuis et al., 2015). Studies have reported higher decayed, missing, or filled teeth and plaque scores in patients with craniosynostosis, putting more pressure on delivering enhanced dental follow-up programs and aiding in achieving proper oral hygiene (Mustafa et al., 2001; Dalben et al., 2006; Vargervik et al., 2012). Dental maturity should be considered in orthodontic treatment planning for proper timing of treatment (Stojkovic et al., 2016).

\section{Conclusion}

In this study, we found a higher prevalence of dens invaginatus in patients with isolated craniosynostosis, with dental maturity also being advanced in these patients. Prophylactic care is important for invaginated and taurodontic teeth.

\section{Authors' Note}

Preliminary results of this study were orally presented at the European Cleft Palate and Craniofacial Association's (ECPCA) Congress on June 13, 2019, in Utrecht, Netherlands.

\section{Declaration of Conflicting Interests}

The author(s) declared no potential conflicts of interest with respect to the research, authorship, and/or publication of this article.

\section{Funding}

The author(s) disclosed receipt of the following financial support for the research, authorship, and/or publication of this article: The corresponding author received a grant of $€ 1200$ for the ECPCA Congress presentation from the Finnish Dental Society Apollonia.

\section{ORCID iD}

Sami Leinonen, DDS (1) https://orcid.org/0000-0003-0680-2269

Arja Heliövaara, DDS, PhD (D) https://orcid.org/0000-0001-8064-3 484

\section{References}

Al-Ani AH, Antoun JS, Thomson WM, Merriman TR, Farella M. Hypodontia: an update on its etiology, classification, and clinical management. Biomed Res Int. 2017;2017(1):9378325.

Anderson PJ, Hall CM, Evans RD, Hayward RD, Jones BM. The hands in Saethre-Chotzen syndrome. J Craniofac Genet Dev Biol. 1996;16(4):228-233.

Arte S, Nieminen P, Apajalahti S, Haavikko K, Thesleff I, Pirinen S. Characteristics of incisor-premolar hypodontia in families. $J$ Dent Res. 2001;80(5):1445-1450.

Baron C, Houchmand-Cuny M, Enkel B, Lopez-Cazaux S.Prevalence of dental anomalies in French orthodontic patients: a retrospective study. Arch Pediatr. 2018;25(7):426-430.

Bessenyei B, Nagy A, Szakszon K, Mokánszki A, Balogh E, Uljfalusi A, Tihanyi M, Novák L, Bognár L, Oláh É. Clinical and genetic characteristics of craniosynostosis in Hungary. Am J Med Genet A. 2015;167A(12):2985-2991.

Bhatt AP, Dholakia HM. Radicular variety of double dens invaginatus. Oral Surg Oral Med Oral Pathol. 1975;39(2):284-287.

Bilge NH, Yesiltepe S, Torenek Agirman K, Caglayan F, Bilge OM. Investigation of prevalence of dental anomalies by using digital panoramic radiographs. Folia Morphol (Warsz). 2018;77(2): 323-328.

Boulet SL, Rasmussen SA, Honein MA. A population-based study of craniosynostosis in metropolitan Atlanta, 1989-2003. Am J Med Genet A. 2008;146A(8):984-991.

Capar ID, Ertas H, Arslan H, Tarim Ertas E. A retrospective comparative study of cone-beam computed tomography versus rendered panoramic images in identifying the presence, types, and 
characteristics of dens invaginatus in a Turkish population. $J$ Endod. 2015;41(4):473-478.

Chhabra N, Goswami M, Chhabra A. Genetic basis of dental agenesis-molecular genetics patterning clinical dentistry. Med Oral Patol Oral Cir Bucal. 2014;19(2):112-119.

Christian EA, Imahiyerobo TA, Nallapa S, Urata M, McComb JG, Krieger MD. Intracranial hypertension after surgical correction for craniosynostosis: a systematic review. Neurosurg Focus. 2015; 38(5):E6.

Cicchetti DV. Guidelines, criteria, and rules of thumb for evaluating normed and standardized assessment instruments in psychology. Psychol Assess. 1994;6(4):284-290.

Cornelissen M, Den Ottelander B, Rizopoulos D, van der Hulst R, van der Molen AM, van der Horst C, Delye H, van Veelen ML, Bonsel G, Mathijs sen I. Increase of prevalence of craniosynostosis. $J$ Craniomaxillofac Surg. 2016;44(9):1273-1279.

Dalben Gda S, Costa B, Gomide MR. Oral health status of children with syndromic craniosynostosis. Oral Health Prev Dent. 2006; 4(3):173-179.

De Coster PJ, Marks LA, Martens LC, Huysseune A.Dental agenesis: genetic and clinical perspectives. J Oral Pathol Med. 2009;38(1): $1-17$.

Demirjian A, Goldstein H, Tanner JM. A new system of dental age assessment. Hum Biol. 1973;45(2):211-227.

Di Rocco F, Arnaud E, Renier D. Evolution in the frequency of nonsyndromic craniosynostosis. J Neurosurg Pediatr. 2009;4(1): 21-25.

French LR, Jackson IT, Melton LJ III. A population-based study of craniosynostosis. J Clin Epidemiol. 1990;43(1):69-73.

Gallacher A, Ali R, Bhakta S.Dens invaginatus: diagnosis and management strategies. Br Dent J. 2016;221(7):383-387.

Goncalves-Filho AJ, Moda LB, Oliveira RP, Ribeiro AL, Pinheiro JJ, Alver-Junior SR. Prevalence of dental anomalies on panoramic radiographs in a population of the state of Para, Brazil. Indian $J$ Dent Res. 2014;25(5):648-652.

Gunduz K, Celenk P, Canger EM, Zengin Z, Sumer P. A retrospective study of the prevalence and characteristics of dens invaginatus in a sample of the Turkish population. Med Oral Patol Oral Cir Bucal. 2013;18(1):27-32.

Heliovaara A, Vuola P, Hukki J. Craniofacial cephalometric morphology in 8-year-old children with operated sagittal synostosis. Orthod Craniofac Res. 2015;18(1):27-32.

Jafarzadeh H, Azarpazhooh A, Mayhall JT. Taurodontism: a review of the condition and endodontic treatment challenges. Int Endod J. 2008;41(5):375-388.

Jernvall J, Thesleff I.Tooth shape formation and tooth renewal: evolving with the same signals. Development. 2012;139(19):3487-3497.

Johnson D, Wilkie AO. Craniosynostosis. Eur J Hum Genet. 2011; 19(4):369-376.

Kajdic N, Spazzapan P, Velnar T. Craniosynostosis-recognition, clinical characteristics, and treatment. Bosn J Basic Med Sci. 2018;18(2):110-116.

Kieser JA. Odontogenic polarity and butler's field theory. Med Hypotheses. 1986;20(1):103-107.

Knight SJ, Anderson VA, Spencer-Smith MM, Da Costa AC. Neurodevelopmental outcomes in infants and children with single-suture craniosynostosis: a systematic review. Dev Neuropsychol. 2014; 39(3):159-186.

Ko JM. Genetic syndromes associated with craniosynostosis. J Kor Neurosurg Soc. 2016;59(3):187-191.

Lagana G, Venza N, Borzabadi-Farahani A, Fabi F, Danesi C, Cozza P.Dental anomalies: prevalence and associations between them in a large sample of non-orthodontic subjects, a cross-sectional study. BMC Oral Health. 2017;17(1):62.

Lajeunie E, Le Merrer M, Bonaiti-Pellie C, Marchac D, Renier D. Genetic study of nonsyndromic coronal craniosynostosis. Am J Med Genet. 1995;55(4):500-504.

Lebuis A, Bortoluzzi P, Huynh N, Bach N. Occlusal relations in patients with scaphocephaly. J Craniofac Surg. 2015;26(6): 1893-1899.

Leikola J, Koljonen V, Heliövaara A, Hukki J, Koivikko M. Cephalic index correlates poorly with intracranial volume in non-syndromic scaphocephalic patients. Childs Nerv Syst. 2014;30(12): 2097-2102.

Llamas R, Jimenez-Planas A. Taurodontism in premolars. Oral Surg Oral Med Oral Pathol. 1993;75(4):501-505.

Maliepaard M, Mathijssen IM, Oosterlaan J, Okkerse JM. Intellectual, behavioral, and emotional functioning in children with syndromic craniosynostosis. Pediatrics. 2014;133(6):e1608-e1615.

Melo M, Ata-Ali J. Accuracy of the estimation of dental age in comparison with chronological age in a Spanish sample of 2641 living subjects using the Demirjian and Nolla methods. Forensic Sci Int. 2017;270:276.e1-e7.

Mustafa D, Lucas VS, Junod P, Evans R, Mason C, Roberts GJ. The dental health and caries-related microflora in children with craniosynostosis. Cleft Palate Craniofac J. 2001;38(6):629-635.

Neves FS, dos Anjos Pontual A, Campos PSF, Frazão MAG, de Almeida SM, de Moraes Ramos-Perez, Maria F. Radicular dens invaginatus in a mandibular premolar: cone-beam computed tomography findings of a rare anomaly. Oral Radiol. 2013; 29(1):70-73.

Nystrom M, Aine L, Peck L, Haavikko K, Kataja M. Dental maturity in Finns and the problem of missing teeth. Acta Odontol Scand. 2000;58(2):49-56.

Oehlers FA.Dens invaginatus (dilated composite odontome). I. Variations of the invagination process and associated anterior crown forms. Oral Surg Oral Med Oral Pathol. 1957;10(11):1204-1218 contd.

Oehlers FA. The radicular variety of dens invaginatus. Oral Surg Oral Med Oral Pathol. 1958;11(11):1251-1260.

Pelo S, Marianetti TM, Cacucci L, Di Nardo F, Borrelli A, Di Rocco C, Tamburrini G, Moro A, Gasparini G, Deli R. Occlusal alterations in unilateral coronal craniosynostosis. Int J Oral Maxillofac Surg. 2011;40(8):805-809.

Reitsma JH, Ongkosuwito EM, van Wijk AJ, Prahl-Andersen B. Patterns of tooth agenesis in patients with Crouzon or Apert syndrome. Cleft Palate Craniofac J. 2014a;51(2):178-183.

Reitsma JH, Balk-Leurs IH, Ongkosuwito EM, Wattel E, PrahlAndersen B. Dental maturation in children with the syndrome of Crouzon and Apert. Cleft Palate Craniofac J. 2014b;51(6): 639-644. 
Rice DP, Rice R, Thesleff I. Molecular mechanisms in calvarial bone and suture development, and their relation to craniosynostosis. Eur J Orthod. 2003;25(2):139-148.

Shashirekha G, Jena A. Prevalence and incidence of gemination and fusion in maxillary lateral incisors in Odisha population and related case report. J Clin Diagn Res. 2013;7(10): 2326-2329.

Shifman A, Chanannel I. Prevalence of taurodontism found in radiographic dental examination of 1,200 young adult Israeli patients. Community Dent Oral Epidemiol. 1978;6(4): 200-203.

Sobieska E, Fester A, Nieborak M, Zadurska M. Assessment of the dental age of children in the Polish population with comparison of the Demirjian and the Willems methods. Med Sci Monit. 2018;24: 8315-8321.

Stojkovic G, Stojkovic M, Stojkovic J, Nikolic D, Stajcic Z. Comprehensive surgical. Orthodontic treatment of class III malocclusion in cleft patient involving minimally invasive surgery case report and literature review. Ann Ital Chir. 2016;5(Dec 19): S2239253X16026384.

Thesleff I. Current understanding of the process of tooth formation: transfer from the laboratory to the clinic. Aust Dent J. 2014; 59(suppl 1):48-54.

Timberlake AT, Persing JA. Genetics of nonsyndromic craniosynostosis. Plast Reconstr Surg. 2018;141(6):1508-1516.
Tulensalo T, Ranta R, Kataja M. Reliability in estimating taurodontism of permanent molars from orthopantomograms. Community Dent Oral Epidemiol. 1989;17(5):258-262.

Twigg SR, Wilkie AO. A genetic-pathophysiological framework for craniosynostosis. Am J Hum Genet. 2015;97(3):359-377.

Vargervik K, Rubin MS, Grayson BH, Figueroa AA, Kreiborg S, Shirley JC, Simmons KE, Warren SM. Parameters of care for craniosynostosis: dental and orthodontic perspectives. Am J Orthod Dentofacial Orthop. 2012;141(4 supp1):68-73.

Vilan Xavier AC, Pinto Silva LC, Oliveira P, Villamarim Soares R, de Almeida Cruz R. A review and dental management of persons with craniosynostosis anomalies. Spec Care Dentist. 2008;28(3):96-100.

Wilkie AOM, Johnson D, Wall SA. Clinical genetics of craniosynostosis. Curr Opin Pediatr. 2017;29(6):622-628.

Willems G, Van Olmen A, Spiessens B, Carels C.Dental age estimation in Belgian children: Demirjian's technique revisited. J Forensic Sci. 2001;46(4):893-895.

Woods E, Parekh S, Evans R, Moles DR, Gill D. The dental development in patients with Aperts syndrome. Int J Paediatr Dent. 2015; 25(2):136-143.

Yuan Y, Chai Y. Regulatory mechanisms of jaw bone and tooth development. Curr Top Dev Biol. 2019;133:91-118.

Zhu J, Wang X, Fang Y, Von den Hoff JW, Meng L. An update on the diagnosis and treatment of dens invaginatus. Aust Dent J. 2017; 62(3):261-275. 